decay : each new atom produced was similarly timeextended, stemmed from a parent atom, and consisted of existentially dependent parts, but it was not dependent on its environment analogously to a cell. In elementary-particle theory, explanation might amount to little more than classification, or an enumeration of possibilities, and might have little more predictive power than comparable biological models with their over-determination and multiplecausation. The chairman, Prof. C. F. A. Pantin, referred to the occurrence, in biology, of morphological models that can be interpreted at more than one level in an organizational hierarchy. In discussion it was suggested that the predictive power of a theory might not always be manifest at the time of its original formulation; it might have to await development of deduction. There was much interest in the relative importance of the past history of an entity in biology and in physics : historical existential dependence appears to be a function of complexity.

In the third session, with Mr. G. Buchdahl in the chair, Miss M. Masterman and Mr. R. M. Needham presented the strategy, and some of the tactics, of a method of analysing language by assimilating it to a library classification system in which concepts are arranged on a finite lattice ordered by a single, weak, 'concordance' (inclusion) relation. They further suggested that the formation of scientific concepts is a development of language according to this model. There was some discussion as to whether the method is a technology for mechanical translation, or a science, or a philosophy of language, and it was suggested that it could be viewed as a scientific model of language, containing the partly uninterpreted concept 'inclusion', and capable of being tested by experiments on translation and on analogyfinding.

In the fourth session, under the chairmanship of of Dr. W. H. Thorpe, Prof. M. Polanyi presented a way of talking about the primary process of knowing by perception, the pre-articulate act of knowing, which partakes of the uniqueness of the individual percipient, the unspecifiable personal knowledge from which any specifiable, potentially public, knowledge is derived by a process of abstraction. Complex entities were commonly perceived and recognized as wholes before particulars had been identified; the process of discovery, in fact, might be regarded as an alternation of analysis, recognizing particulars, and integration, recognizing the relations of parts to the whole. Prof. R. B. Braithwaite suggested that too narrow a view might be taken of specifiability, and that some levels of subjective experience, however vague, could be conveyed by language-for example, 'Oblomov' conveys the experience of laziness; beyond that, he differed from Prof. Polanyi in his use of the term 'knowledge' for what was unspecifiable. In the subsequent discussion there was some reluctance to focus on this rather undemocratic mode of tacit awareness, and a preference for talking about what can be made public, with the implication that the progressive refinement of scientific language tends to eliminate the unspecifiable.

In conclusion, it is perhaps worth directing attention to the unusualness of a scientific conference at which speakers are not armed with specified and verifiable data but attend primarily to make as explicit as possible how they think, and to receive criticism of the process thereby revealed, especially from those who are not working in the same field. The coherence of this universe of discourse was illustrated by the frequency of reference from one discussion to another, the esprit d'escalier from one session often finding its outlet in a later one ; its range, by the frequency of spontaneous quotation, not only from Shakespeare and Wordsworth but also from Swinburne (and early Swinburne, at that).
G. E. DENYER

\title{
FOURTEENTH ANNUAL CALORIMETRY CONFERENCE
}

\begin{abstract}
$\mathrm{T}$ HE fourteenth annual Calorimetry Conference, held at Yale University in the Sterling Chemistry Laboratory during September 10-12, was attended by more than one hundred scientists from the United States, Canada and Europe. Under the chairmanship of Dr. David White (Ohio State University) thirty papers were read and discussed. These included: heat capacity measurements at temperatures as low as $0.1^{\circ} \mathrm{K}$. and as high as $1,400^{\circ} \mathrm{K}$.; precision reaction and bomb calorimetry; solution calorimetry; and determinations of stored energy in solids.

Most of the papers were concerned with recent developments in calorimetry. However, as calorimetric techniques are extended to more extreme conditions, the problems that led to the founding of the Conference remain under new guises. The need for better temperature measuring devices was emphasized in seven papers that reported on research at temperatures below $11^{\circ} \mathrm{K}$. No device comparable to the platinum resistance thermometer, now in general use for measurements above $11^{\circ} \mathrm{K}$., is yet available for the very low temperatures at which some of the most important calorimetric
\end{abstract}

research is now being done. However, the reports on a device that may extend precision thermometry to at least $1^{\circ} \mathrm{K}$., namely, the germanium resistance thermometer developed in the Bell Telephone Laboratories, were received enthusiastically. Twelve of these thermometers had been provided for a calorimetry conference test programme involving eleven different laboratories. Three papers at the Yale conference described the first results of the investigations, which were so promising that the Conference plans to seek a manufacturer of additional units for a more extensive testing programme.

Special addresses were given by Profs. George S. Parks (Stanford University) and Lars Onsager (Yale University). At the annual banquet, Parks delivered the Hugh M. Huffman Memorial Lecture, "Some Remarks on the Thermodynamic Properties of Organic Compounds". Parks and one of his first graduate students, the late Dr. Huffman, started the first systematic calorimetric studies of organic compounds at Stanford more than thirty years ago. Enlivening his remarks with many personal anecdotes, Parks traced the history of thermodynamic research on organic substances and the role improvement 
of calorimetric methods has taken in the remark able progress made in the past three decades. Prof. Onsager gave the principal lecture of the technical sessions on "Co-operative Phenomena", a field in which he has developed much of the basic theory. Many papers at each Calorimetry Conference describe experimental studies of co-operative phenomena, and Onsager outlined the approaches one may take in seeking a theoretical understanding of such effects. Admitting that three-dimensional treatments of critical phenomena by statistical mechanics seem hopelessly complex, he dwelt mostly on more simplified treatments that give results.

In addition to the objective of promoting better calorimetric research, the Conference also is concerned with publication policies relating to calorimetric and thermodynamic articles. A "Resolution regarding Published Calorimetric Data" adopted by the eighth Conference in 1953 has proved to be valuable to editors and authors alike in establishing consistent policies based on the opinions of experts in the field. Because calorimetric research has expanded into many areas not covered by the 1953 resolution, the fourteenth Conference established a committee headed by J. P. McCullough to consider revising and extend. ing the earlier recommendations. Drs. Edgar F.
Westrum, jun. (University of Michigan), and Stig Sunner (University of Lund, Sweden) presented a proposal of the Commission on Thermodynamics of the International Union of Pure and Applied Chemistry for a joint meeting in 1961 of the Calorimetry Conference and the Subcommissions on Experimental Thermochemistry and Experimental Thermodynamics. The Conference unanimously approved the proposal for a joint meeting to be held either before or after the biennial meeting of the Union that year in Montreal, Canada. Plans will begin immediately for what should be one of the most important eonferences ever held in the field of calorimetry.

At the annual election the following members were appointed to Conference offices: Chairman, Dr. J. P. McCullough (Petroleum Thermodynamics Laboratory, Bureau of Mines); Chairman-Elect, Dr. D. W. Osborne (Argonne National Laboratory); Directors, 1959-62, Dr. N. E. Phillips (University of California, Berkeley) and Dx. J. M. Sturtevant (Yale University). Other officers include: SecretaryTreasurer, Dr. C. E. Messer (Tufts University) and Directors, Dr. David White, Dr. D. H. Andrews (Johns Hopkins University), Dr. J. E. Kunzler (Bell Telephone Laboratories), and Dr. J. A. Morrison (National Research Council, Ottawa).

\section{SECOND AUSTRALIAN SPECTROSCOPY CONFERENCE}

T HE second Australian Spectroscopy Conference, convened by Dr. A. L. G. Rees (Division of Chemical Physics, Commonwealth Scientific and Industrial Research Organization) and held in the Chemistry Department of the University of Melbourne during June 1-3, was opened by Prof. J. S. Anderson, who welcomed the 110 participants and the four exhibitors of commercial spectroscopic equipment. The first session of the conference was devoted to ultra-violet spectra and began with a review by Prof. N. S. Bayliss (Chemistry Department, University of Western Australia) of recent theoretical work on solvent effects. He directed attention to the calculations of Polansky on the interaction between two $\mathrm{H}$ atoms which predict a red shift in the atomic spectrum beyond a critical distance and a blue shift at closer distances, to the calculations by Longuet-Higgins and Pople of the red shift in the spectra of non-polar solutes in non-polar solvents arising from dispersive forces, and to McRee's formulations of the case of polar solute and polar solvent. The McRae formula predicts a frequency shift between absorption and fluorescence arising from the change of dipole moment between the ground and excited states, thus providing a method for measuring the dipole moments of excited states for comparison with calculated values.

One set of contributed papers in this section dealt with the spectra of aromatic hydrocarbons. Drs. G. R. Hunt and I. G. Ross (Physical Chemistry Department, University of Sydney) discussed a vibrational analysis of the $7000 \mathrm{~A}$. and $3500 \mathrm{~A}$. absorption systems of azulene which appears to confirm the predictions of Pariser and of Moffitt concerning the nature of the excited states. Dr. L. E. Lyons and Mr. G. C. Morris (Physical Chemistry Department, University of Sydney) presented results on the absorption of anthracene vapour $(38,000$ to $\left.60,000 \mathrm{~cm}^{-1}\right)$. They confirmed the second $\pi-\pi$ transition as allowed and also observed four members of a Rydberg series converging to an ionization potential of $6.81 \mathrm{eV}$. Dr. N. S. Ham (Division of Chemical Physics, Commonwealth Scientific and Industrial Research Organization) reported some calculations by the free-electron model, with electronic interaction, of the spectrum of the perinaphthenylium cation $\mathrm{C}_{13} \mathrm{H}_{9}{ }^{+}$, which agree well with the reported spectrum and also predict an unreported absorption band at about $600 \mu$.

Studies by Dr. I. G. Ross and E. J. Wells (Physical Chemistry Dopartment, University of Sydney) on the interesting tetrahedral molecules $\mathrm{OsO}_{4}$ and $\mathrm{RuO}_{4}$ failed to reproduce the extensive fine structure reported in the room temperature spectra by Langseth and Qviller in 1934. The authors gave a vibrational analysis of their spectra and used the energy-lovel scheme of Ballhausen and Liehr to assign the two allowed transitions. A theoretical paper by Dr. E. G. McRae (Division of Chemical Physics, Commonwealth Scientific and Industrial Research Organization) was concerned with electronically excited states of aggregated identical molecules; the intra-molecular vibrations were explicitly included. Two limiting cases were recognized, depending on whether the interaction onergy was large or small with respect to the vibrational energy. An interpretation of the $J$ band of N,N'-diethyl-pseudo-cyanine was offered on the basis of this theory.

Dr. H. A. McKenzie (Division of Food Preservation and Transport, Commonwealth Scientific and Industrial Research Organization) spolse on the difference spectra in acid solutions and in urea solutions of bovine serum albumin, ovalbumin and conalbumin.

Dr. L. E. Lyons (Physical Chemistry Department, University of Sydney), in opening the session on solid state spectroscopy, described a number of the effects 